\title{
INFLUENCING FACTORS OF RUNWAY INCURSION RISK AND THEIR INTERACTION MECHANISM BASED ON DEMATEL-ISM
}

\author{
Pan-ke Zhang, Fan Luo
}

Original scientific paper

Runway incursion is the safety management core of civil airports, and the influencing factor of runway incursion is a hot topic in the practical and academic circles. To identify key influencing factors and determine interaction ways, typical runway incursions were analyzed using the softwarehardware-environment-liveware model (SHELL). Fifteen influencing factors were identified and extracted. The centrality and cause of influencing factors were calculated by decision-making trial and evaluation laboratory (DEMATEL) and interpretative structural modelling (ISM). A multi-layer interpretative structural model was constructed for layering of influencing factors. Results indicate that inadequate attention of airport leaders to safety is the root factor. System formulation and educational training are deep influencing factors. Oversight and the operation error rate of ground officials are direct influencing factors. Runway incursion could be fundamentally controlled and prevented by improving the root factor. The proposed DEMATELISM method can analyze the influencing factors of runway incursions and their influencing mechanism, thereby offsetting the shortcomings of the linear risk factor statistical model and offering a novel decision-making idea and approach for runway incursion control.

Keywords: DEMATEL; ISM; interaction mechanism; risk analysis; runway incursion

Utjecajni čimbenici rizika za upad na pistu i njihov mehanizam interakcije temeljen na DEMATEL-ISM

Izvorni znanstveni članak

Upad na pistu je središnja jezgra sigurnosti civilnih zračnih luka, a čimbenik koji utječe na upad na pistu je vruća tema u praktičnim i akademskim krugovima. Da bi identificirali ključne čimbenike koji utječu i utvrdili načine interakcije, uobičajeni upadi na pistu analizirani su pomoću modela softverhardver-okruženje-osoblje (SHELL). Utvrđeno je i izdvojeno petnaest vrsta utjecaja. Usmjernost i uzrok utjecajnih čimbenika izračunati su pomoću probnog i evaluacijskog laboratorija (DEMATEL) i interpretativnog strukturnog modeliranja (ISM). Izrađen je višeslojni interpretativni strukturni model za raslojavanje čimbenika koji utječu na njih. Rezultati pokazuju da je temeljni čimbenik neodgovarajuća pozornost čelnika zračne luke prema sigurnosti. Formuliranje sustava i edukacijsko obrazovanje su čimbenici od najvećeg utjecaja. Previd i stopa pogrešaka u radu službenika na tlu izravni su utjecajni čimbenici. Upad na pistu mogao bi se temeljito kontrolirati i spriječiti poboljšavanjem temeljnog čimbenika. Predložena metoda DEMATEL-ISM može analizirati čimbenike koji utječu na upade na pistu i mehanizam koji dovodi do njih, čime se nadoknađuju nedostaci statističkog modela linearnog faktora rizika i nudi nova ideja odlučivanja i pristupa za kontrolu upada na pistu.

Ključne riječi: analiza rizika; DEMATEL; ISM; mehanizam interakcije; upad na pistu

\section{Introduction}

Safety incidents caused by runway incursion in airports have been increasingly frequent in recent years. Transport Canada reported that the $20 \%$ growth of airport traffic will increase runway incursion risk by $140 \%$. Runway incursion is widely accepted as one of the most important risk sources in civil aviation airports. According to the International Civil Aviation Organization (ICAO), runway incursion refers to any occurrence at an aerodrome involving the incorrect presence of an aircraft, vehicle, or person on the protected area of a surface designated for the landing and take-off of aircraft. The airport surface protection zone in an airport covers the runway, taxiway, and soil surface areas at two sides within $75 \mathrm{~m}$ to the middle line of the runway. Runway incursion is not only sensitive to environment and hardware systems (e.g. airport facilities, meteorological conditions, and aircraft state), but is also closely related to the judgment and operation of aviators and air traffic controllers and the management behaviors of airport officials. In addition, a complicated relationship exists among the different factors. Therefore, identifying influencing factors and their interaction mechanism and determining risk transmission paths are the bases of effective incursion risk control.

However, most of the existing studies on runway incursion influencing factors focus on the statistical analysis of the improper behaviors of subjects, such as pilots, air traffic controllers, personnel, and vehicles $[1,2]$.
Insufficient attention is given to organizational factors (e.g. safety training, system performance, safety culture, and organization culture) and internal psychological factors (e.g. safety consciousness, skill and experiences, and job burnout). Studies on the evolution mechanism of runway incursion are mainly based on multi-agent modeling simulations and analyze impacts of human error through temporal and logical ideas [3]. Moreover, the hierarchy and interaction of risk factors are hardly discussed in studies concerning the assessment of runway incursion risk. Existing research on runway incursion mainly highlights the behavioral mistakes of subjects, but hardly discusses organization management factors, the psychological factors of employees, and the interaction of influencing factors, especially the causality and action mechanism of influencing factors. In this study, the influencing factors of runway incursion were screened from the personnel, machine, environment, and management perspectives. The relationship and relation strength among different factors were analyzed. Root factors and deep and direct influencing factors were identified and the risk transmission paths in the system were determined. Countermeasures to runway incursion were proposed to reduce runway incursion risks.

\section{State of the art}

With respect to the influencing factors of runway incursion, existing studies mainly analyzed the correlation between the incursion data and the influencing factors and 
determined the influence degrees of every factor through mathematical statistics. Huo and Han [1] performed multiple regression analyses of incursion results and influencing factors through the least square method and found that typical error influences runway incursion significantly. They concluded that improper airfield management, runway invasion of people and vehicles, poor coordination in civil and military airports, insufficient personnel training, and the absence of runway incursion consciousness are the main influencing factors. Zhang and Yang [2] analyzed the correlation between accident causes, namely, pilot deviation (PD), operational error/deviation (OE/OD), and vehicle/pedestrian deviation (V/PD), and event severity. They reported that the key to preventing $\mathrm{A}$ and $\mathrm{B}$ types of runway incursion is to enhance the access administration of pedestrian and vehicle drivers to the airfield and improve the quality of their communication, while the key to preventing $C$ and D types of runway incursion is to train pilots to obey laws and rules. Luo, Liu, and $\mathrm{Li}$ [4] determined the scale and the weight coefficient of accident causes based on the G1 method and expert empirical analysis, including minimum approaching distance, visibility/runway visual range/cloud base height, runway braking condition, remedial measure, communication status, controller deviation, and pilot deviation, and constructed a mathematical algorithm model of runway incursion severity. Feigh and Bruneau [5] pointed out from the statistical analysis of accidents that over one-third of the most serious runway incursions are caused by PD, and the absence of situational awareness is the major cause of PD. Adam et al. [6] discussed the human risks of runway incursion and believed that most runway incursions are induced by the collaborative effect of multiple factors instead of their independent effects. Chang [7] argued that runway incursions are often caused by human mistakes, especially PD. PD mainly covers six aspects: pilot core competence, pilot-employee interaction, pilotorganization interaction, pilot-environment interaction, pilot-software interaction, and pilot-hardware interaction.

Numerous research results of runway incursion risk assessment exist. They generally follow the steps of index screening, weight determination, and comprehensive assessment. Fuzzy set theory, TOPSIS method [8], Gaussian Bayesian network model [9], event tree analysis (ETA), and cognitive reliability and error analysis method (CREAM) [10] are the major research methods. Kim and Yang et al. [11] determined the weights of the influencing factors of runway incursion in the Gimpo International Airport in Korea through the analytic hierarchy process (AHP). They assessed the possibility and harmfulness of runway incursion risks through the fault tree analysis and found that human mistakes can influence runway incursion risk significantly. Lin [12] divided the influencing factors of runway incursion into superficial and implicit factors, constructed the Gaussian Bayesian network model of runway incursion, and analyzed the causes and mechanism of runway incursion according to the direct relationships of factors and conditional probability. Gao and Luo [13] discussed the hidden danger, possible causes, and consequences of runway incursion based on the Bowtie model. They emphasized risk and organization control. Several researchers have assessed runway incursion risk using other methods. For example, Tian and Zhou et al. [3] analyzed the evolution mechanism of runway incursion risks based on the multiagent dynamic simulation method. From the variability and interaction of a complicated system, Stroeve and Blom et al. [14] assessed the safety risk of runway incursion by establishing a sequential epidemics accident model and implemented a simulation using the Monte Carlo method. Landry and Chen et al. [15] recognized and tested runway incursion risks based on the complex network theory and established and verified the model of Hartsfield International Airport in Atlanta.

To sum up, existing studies on runway incursion give significant attention to direct causes, such as the operation error and deviation of frontline staffs, including pilots, air traffic controllers, and ground officials, whereas the management and psychological factors of employees are hardly discussed. Existing studies emphasize mathematical statistics, comprehensive evaluation, and behavioral simulation analysis rather than the mechanism of runway incursion and the interaction of different factors. The influencing mechanism of risk factors and the evolution process of runway incursions remain a mystery.

Considering the shortcomings of existing studies, the influencing factors of runway incursion were identified in this study through the SHELL model. The influencing factors were extracted and defined by combining case study and questionnaire survey. An impact matrix was established by the decision-making trial and evaluation laboratory (DEMATEL) method to calculate the centrality and cause of influencing factors. Influencing factors with strong interaction were screened by setting a threshold, and all interactions were determined by interpretative structural modelling (ISM), which helps controllers comprehend the keys of risk control.

The rest of this study is organized as follows. Section 3 introduces the method for extracting the influencing factors of runway incursion, the establishment of the impact and reachable matrices, the calculation of centrality and cause, and ISM construction. Section 4 presents the result analysis. Section 5 summarizes the conclusions.

\section{Methodology 3.1 Analysis of influencing factors}

The extraction of influencing factors is the basis for analyzing the influencing mechanism. The influencing factors of runway incursion cover human, aircraft, environment, and management, including subject (pilot, air traffic controllers, and ground vehicle drivers) errors, organization safety management, safety environmental factors, and safety facilities. Combinations of influencing factors were analyzed using the SHELL model. In the SHELL model, $\mathrm{S}$ stands for software, $\mathrm{H}$ stands for hardware, E stands for environment, and $\mathrm{L}$ stands for liveware. Four components in the SHELL model are dependent on each other and the interfaces between staff factors and other factors. L-L relationships mainly include support, cooperation, and communication. L-H interprets the relationship between related works and airborne equipment. These interfaces are as follows: 
(1) L-H interface. It reflects interactions between related workers and airborne equipment, navigation equipment, and airport surface equipment. L-H interface influences the interaction degree between workers and machines in real operations, such as reasonable cabin altitude and recognizable light color switchover device.

(2) L-S interface. It reflects the interactions between workers in the workplace and the applied software or documents of the Airline Company or Air Traffic Management Bureau, such as standard operation manual, computer program software, and table of aircrafts.

(3) L-L interface. It refers to the cooperation and coordination of related workers when protecting the safety operation of aircrafts, such as the final decision of the management layer of different departments, the cooperation between the unit and the air traffic controller, the cooperation between air traffic controllers, and the coordination and communication between ground officials and air traffic controllers.

(4) L-E interface. It refers to the adaptation of workers to internal and external environments and their relationship. Internal environment mainly includes cockpit environment, control room environment, and enterprise culture of units, while external environment mainly refers to policies or the macroscopic control of the country and the civil airline company.

The influencing factors of runway incursion were extracted by combining the SHELL model and a typical case study. They were further screened according to a questionnaire survey, and the final influencing factor set was determined.

\subsection{Influencing factor model of runway incursion}

Both DEMATEL and ISM are system structural modeling approaches. They analyze the relationship between any two factors in the system using matrices and the graph theory. DEMATEL emphasizes calculating the direct relation strength in the system, distinguishing causal and consequence factors, identifying the key factors of a complicated system and their influence degrees. ISM emphasizes decomposing a complicated system into several subsystems according to the relationships of factors and constructing a hierarchical ISM. The organic combination of DEMATEL and ISM cannot only analyze the hierarchical structure of the complicated system comprehensively, but can also identify the key factors in the system and their influence degrees. The analysis steps are shown in Fig. 1 [16].

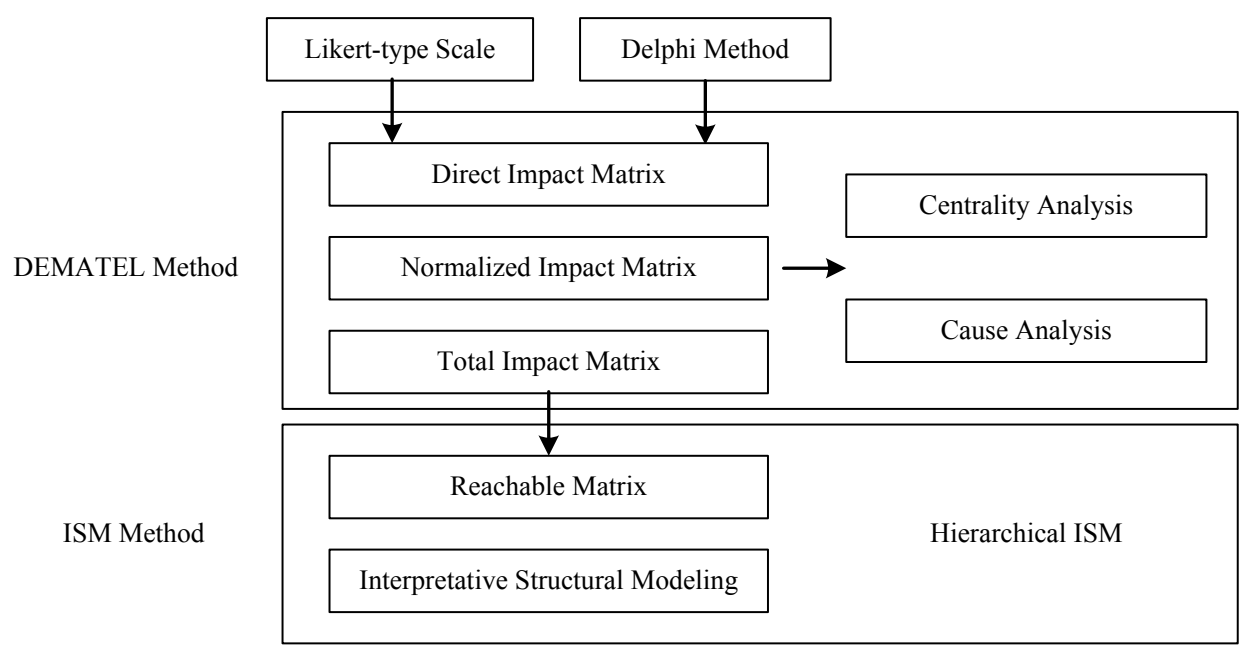

Figure 1 Calculation steps of DEMATEL-ISM method

\subsubsection{Direct impact matrix}

The direct impact degree and the impact matrix among different factors are determined. The relation strength between two factors is evaluated into five classes using a 5-point Likert-type scale and the Delphi method as follows: very strong (4), strong (3), general (2), weak $(1)$, and unrelated (0). The relationship and relation strength among influencing factors are judged by civil aviation and airport management experts. According to the investigation results, the direct impact matrix $\boldsymbol{X}=$ $\left(x_{i j}\right)_{n \times n}$ is obtained, where $x_{i j}$ is the direct impact degree of $A_{i}$ on $A_{j}$ and $x_{i j}=0$ when $i=j$.

\subsubsection{Total impact matrix}

Direct impact matrix $\boldsymbol{X}$ is normalized, and normalized impact matrix $\boldsymbol{D}$ is obtained.

$$
\boldsymbol{D}=\left(1 / \underset{i=1}{\operatorname{Max}} \sum_{j=1}^{n} x_{i j}\right) * \boldsymbol{X}
$$

DEMATEL comprehensively considers the indirect relationship among factors through Eq. (2):

$$
\boldsymbol{T}=\boldsymbol{D} *(\boldsymbol{I}-\boldsymbol{D})^{-1}
$$

where $\boldsymbol{T}$ is the total impact matrix and $\boldsymbol{I}$ is the unit matrix. $T_{i j}$ is the direct and indirect influences of $A_{i}$ on $A_{j}$ or the total influence of $A_{i}$ on $A_{j}$.

\subsubsection{Determination of centrality and cause}

In total impact matrix $\boldsymbol{T}$, the sum of elements in one row shows the total influence of each factor on other factors and is called the degree of impact $(R)$. The sum of elements in one column is the total influence of other 
factors on the corresponding factor and is called the degree of being impacted $(C)$. The sum of $R$ and $C$ is the centrality $(R+C)$, which expresses the role and effect of the factor in the system. The higher the centrality is, the stronger the influence of this factor on runway incursion will be. The difference between $R$ and $C$ is the cause $(R-$ C).

$$
\begin{aligned}
& R=\left[\sum_{i=1}^{n} t_{i j}\right]_{n * 1}=\left[c_{i}\right]_{n * 1} \\
& C=\left[\sum_{j=1}^{n} t_{i j}\right]_{1 * n}=\left[r_{j}\right]_{n * 1}
\end{aligned}
$$

If $R-C>0$, then this factor influences the runway incursion significantly and is more important than the other factors. It influences other factors positively and is a cause factor. If $R-C<0$ then this factor is susceptible to other factors and influences runway incursion indirectly. It is a consequence factor. The cause and consequence factors reflect the impact characteristics of factors. The $R$ and $C$ of every factor can be calculated according to Eq. (3) and Eq. (4), thus the $R+C$ and $R-C$ of the factor can be calculated.

\subsubsection{Reachable matrix}

Weak relations are eliminated by setting a threshold ( $\lambda$ ). The system structure is simplified, and the hierarchical structure is clear. On the basis of the logic judgment from Eq. (5) and Eq. (6), $T$ can be transformed into the reachable matrix $\boldsymbol{K}$, where $k_{i j}$ is the elements of $\boldsymbol{K}$. $\lambda$ influences the composition of $\boldsymbol{K}$ and the subsequent hierarchical structure division. $\lambda$ can be determined by multiple value analyses according to experiences.

$\begin{array}{ll}\text { If } t_{i j} \geq \lambda(i, j=1,2, \ldots, n) & k_{i j}=1 \\ \text { If } t_{i j} \leq \lambda(i, j=1,2, \ldots, n) & k_{i j}=0\end{array}$

\subsubsection{Hierarchical ISM}

On the basis of reachable matrix $\boldsymbol{K}$, the reachable set $R_{i}$ and antecedent set $S_{i}$ of every factor can be determined as follows:

$$
\begin{array}{ll}
R_{i}=\left\{a_{i} \mid a_{j} \in A, k_{i j}=A, k_{i j}=1\right\} & (i, j=1,2, \ldots, n) \\
S_{i}=\left\{a_{i} \mid a_{j} \in A, k_{j i}=A, k_{i j}=1\right\} & (i, j=1,2, \ldots, n)
\end{array}
$$

where $A$ is the factor set.

Depending on whether Eq. (9) or Eq. (10) is true, the risk factor sets of the different levels are divided according to the cause or consequence priority algorithm, thus obtaining the hierarchical ISM of risk factors.

$$
\begin{array}{ll}
R_{i} \cap S_{i}=R_{i} & (i=1,2, \ldots, n) \\
R_{i} \cap S_{i}=S_{i} & (i=1,2, \ldots, n)
\end{array}
$$

\section{Result analysis and discussion 4.1 Influencing factor set of runway incursion}

A total of 149 A-type runway incursion events from 2001-2016 were collected based on the FAA runway incursion database (RWS), including 72 caused by PD (48\%), 59 caused by OE/OD (40\%), and 18 caused by V/PD (12\%). On the basis of the analysis description of runway incursion samples in RWS, the occurrence frequencies of influencing factors were analyzed and ranked using the SHELL model. Those with low occurrence frequency were eliminated. On this basis, influencing factors were further screened through expert interviews through E-mail and telephone and video conferences in December of 2016. All interviewees were scholars of airport safety management or middle and senior managers of enterprises, including 3 from China Academy of Civil Aviation Science and Technology, 5 from CAAC Central and Southern Regional Administration, 5 from the management department of Wuhan Tianhe Airport, and 5 from China Eastern Airlines. Finally, 15 influencing factors (Fig. 2) were recognized by analyzing the interview results. These influencing factors cover employee individuals, operational management, operating conditions, and safety culture. The influencing factor set is $A=\left(A_{i}\right)_{1 * n} i=1,2$, $\ldots, 15$.

\subsubsection{Employee individuals}

Pilot, air traffic controllers, and ground vehicle drivers are subjects who participate directly in runway incursion. Individual factors that influence their mistakes or violation behaviors include biographical characteristics, unqualified knowledge and skill, weak safety consciousness, heavy work load, and high rate of judgment and operational error.

$A_{1}$ : Biographical characteristics. They refer to age; gender; civil status; family composition; educational background; alcohol, tobacco, and drug dependence; and personality characteristics. They can influence the judgment, concentration, and working enthusiasm of subjects directly.

$A_{2}$ : Unqualified knowledge and skill. It reflects the unfamiliarity of subjects on safety knowledge, safety operation rules, tools and equipment, airport layout, signs and environment.

$A_{3}$ : Weak safety consciousness. This means that staff individuals are hardly aware of the external environmental factors that may induce runway incursion and have poor consciousness on safe operation rules, and operation randomness is strong. For example, the pilot does not obey the commands of air traffic controllers strictly and the driver does not obey the commands of running routes and the ground controller strictly.

$A_{4}$ : Heavy work load. It refers to the influences of the working time and intensity of individual staff on their conformation with safe operation rules for the safe running of the working system. Work overload easily decreases the judgment and response rate and increases staff errors.

$A_{5}$ : High rate of judgment and operational error. It refers to the decreased judgment accuracy of pilots, air 
traffic controllers, and drivers caused by negligence, fatigue, and loss of scene consciousness, which lead to incorrect operations or commands. These are often the direct causes of runway incursion.

\subsubsection{Operational management}

Operational management factors that influence runway incursion include oversight of ground officials, absent safety management system, invalid safety management system, and poor safety education.

$A_{6}$ : Oversight of ground officials. It refers to the measures of ground officials to correct, punish, or tolerate the violating behaviors of vehicles and people in the administering region to maintain the smoothness of runway regions.

$A_{7}$ : Absent safety management system. It refers to the imperfect and impractical safety management specifications and systems in airports and the lack of consulting opinions of air traffic controllers, pilots, and other ground officials.

$A_{8}$ : Invalid safety management system. It refers to the ground officials in airports that do not follow safety specifications and systems strictly.

$A_{9}$ : Poor safety education. It refers to the inadequate training of pilots, air traffic controllers, drivers, and ground officials on business skills, safety consciousness, and safety management system.

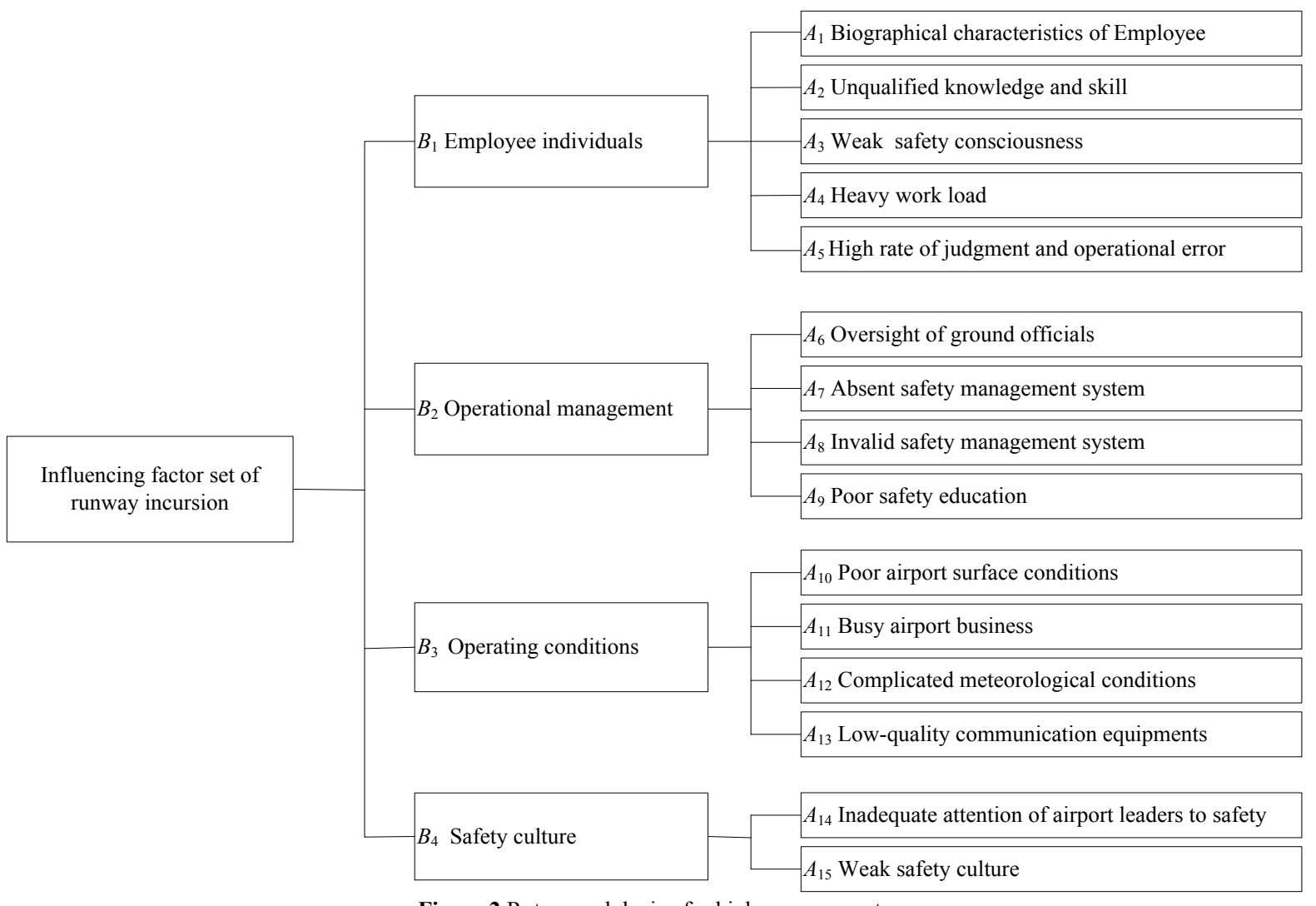

Figure 2 Rotary seal device for high-pressure water

\subsubsection{Operating conditions}

The operating conditions that influence runway incursion include poor airport surface conditions, busy airport business, complicated meteorological conditions, and low-quality communication equipment.

$A_{10}$ : Poor airport surface conditions. Airport surface conditions inadequately satisfy airport operation. Airport surface signs and assisting facilities are not arranged according to the requirements. The airport surface layout is complicated and unreasonable.

$A_{11}$ : Busy airport business. Given limited runways and air traffic control facilities, the more the departure and approaching aircrafts at a unit time are, the higher the runway incursion risk will be.

$A_{12}$ : Complicated meteorological conditions. Meteorological conditions, such as visibility, runway visual range, wind speed, wind direction and shear, and thunderstorm and rainfall, influence the judgment accuracy and maloperation rate of air traffic controllers and pilots directly, thus affecting the taxiing of aircrafts.

$A_{13}$ : Low-quality communication equipments. It reflects the perfection and advance degree of aircrafts, airport scene traffic and communication equipment, friendly degree of human-machine interface, operation difficulty of facilities and equipment, and standard degree of daily maintenance.

\subsubsection{Safety culture}

The safety culture factors of runway incursion include inadequate attention of airport leaders on safety and weak safety culture.

$A_{14}$ : Inadequate attention of airport leaders to safety. Leaders of airports and airlines pay imbalanced attention to safety and production and resource input.

$A_{15}$ : Weak safety culture. It reflects the attitude of the whole organization toward safety and of the staff toward mistakes and the violations of others. 


\subsection{Analysis of centrality and cause}

\subsubsection{Calculate the impact matrix of influencing factor set}

The influencing factors of runway incursion form a complicated system. Different factors have direct and indirect relationships. Relation strength is mainly determined through the Delphi method and the opinions of multiple experts [17]. The 5-point Likert-type scale was designed according to the influencing factor set. A total of 56 questionnaires were sent to the aviation safety experts and airport managers of the China Academy of Civil Aviation Science and Technology, CAAC, Wuhan Tianhe Airport, and China Eastern Airlines from March to April of 2017. Among them, 45 questionnaires were collected, including 21 from professional technicians, 13 from airport managers, and 11 from the frontline staffs of airports. On the basis of the idea of Shaik, Cebi, Hsu and Liou et al. [18-23], questionnaire data were processed by the integrated rule of the averaging method. To protect the scale and the algorithm validity, the average values were rounded-off to determine the direct relation strength between every two factors. The direct impact matrix $(\boldsymbol{X})$ of the influencing factor set was established (Tab. 1).

$X$ was normalized according to Eq. (1) and the total impact matrix $(\boldsymbol{T})$ was calculated according to Eq. (2) (Tab. 2).

Table 1 Direct impact matrix $(\boldsymbol{X})$ of influencing factors of runway incursion

\begin{tabular}{|c|c|c|c|c|c|c|c|c|c|c|c|c|c|c|c|}
\hline$X$ & $A_{1}$ & $A_{2}$ & $A_{3}$ & $A_{4}$ & $A_{5}$ & $A_{6}$ & $A_{7}$ & $A_{8}$ & $A_{9}$ & $A_{10}$ & $A_{11}$ & $A_{12}$ & $A_{13}$ & $A_{14}$ & $A_{15}$ \\
\hline$A_{1}$ & 0 & 4 & 4 & 0 & 3 & 0 & 0 & 0 & 0 & 0 & 0 & 0 & 0 & 0 & 3 \\
\hline$A_{2}$ & 0 & 0 & 4 & 0 & 4 & 3 & 0 & 2 & 0 & 0 & 0 & 0 & 2 & 0 & 2 \\
\hline$A_{3}$ & 0 & 2 & 0 & 0 & 3 & 4 & 0 & 2 & 1 & 2 & 0 & 0 & 2 & 0 & 3 \\
\hline$A_{4}$ & 0 & 0 & 3 & 0 & 0 & 3 & 0 & 4 & 0 & 0 & 0 & 0 & 0 & 0 & 0 \\
\hline$A_{5}$ & 0 & 0 & 0 & 1 & 0 & 0 & 0 & 2 & 0 & 0 & 0 & 0 & 0 & 0 & 0 \\
\hline$A_{6}$ & 0 & 0 & 0 & 2 & 1 & 0 & 0 & 3 & 0 & 0 & 0 & 0 & 2 & 0 & 3 \\
\hline$A_{7}$ & 3 & 3 & 3 & 3 & 2 & 4 & 0 & 4 & 3 & 1 & 0 & 0 & 2 & 0 & 3 \\
\hline$A_{8}$ & 4 & 4 & 3 & 3 & 3 & 4 & 1 & 0 & 3 & 3 & 0 & 0 & 3 & 0 & 4 \\
\hline$A_{9}$ & 0 & 4 & 4 & 0 & 4 & 3 & 1 & 3 & 0 & 1 & 0 & 0 & 2 & 3 & 4 \\
\hline$A_{10}$ & 0 & 0 & 0 & 3 & 4 & 1 & 0 & 0 & 0 & 0 & 1 & 0 & 2 & 0 & 0 \\
\hline$A_{11}$ & 0 & 0 & 0 & 4 & 3 & 3 & 0 & 0 & 2 & 3 & 0 & 0 & 1 & 3 & 3 \\
\hline$A_{12}$ & 0 & 0 & 0 & 4 & 3 & 2 & 0 & 2 & 0 & 3 & 2 & 0 & 2 & 0 & 0 \\
\hline$A_{13}$ & 0 & 0 & 0 & 4 & 0 & 3 & 0 & 0 & 0 & 0 & 2 & 0 & 0 & 0 & 2 \\
\hline$A_{14}$ & 3 & 3 & 4 & 2 & 1 & 4 & 4 & 4 & 3 & 2 & 1 & 0 & 3 & 0 & 4 \\
\hline$A_{15}$ & 1 & 2 & 4 & 1 & 2 & 4 & 3 & 3 & 3 & 1 & 0 & 0 & 1 & 1 & 0 \\
\hline
\end{tabular}

Table 2 Total impact matrix $(\boldsymbol{T})$ of influencing factors of runway incursion

\begin{tabular}{|c|c|c|c|c|c|c|c|c|c|c|c|c|c|c|c|}
\hline$T$ & $A_{1}$ & $A_{2}$ & $A_{3}$ & $A_{4}$ & $A_{5}$ & $A_{6}$ & $A_{7}$ & $A_{8}$ & $A_{9}$ & $A_{10}$ & $A_{11}$ & $A_{12}$ & $A_{13}$ & $A_{14}$ & $A_{15}$ \\
\hline$A_{1}$ & 0.01 & 0.13 & 0.14 & 0.02 & 0.12 & 0.05 & 0.01 & 0.04 & 0.02 & 0.01 & 0.00 & 0.00 & 0.02 & 0.00 & 0.11 \\
\hline$A_{2}$ & 0.01 & 0.03 & 0.13 & 0.03 & 0.14 & 0.13 & 0.01 & 0.09 & 0.02 & 0.02 & 0.00 & 0.00 & 0.08 & 0.00 & 0.09 \\
\hline$A_{3}$ & 0.02 & 0.08 & 0.04 & 0.04 & 0.12 & 0.16 & 0.01 & 0.10 & 0.05 & 0.07 & 0.01 & 0.00 & 0.09 & 0.01 & 0.12 \\
\hline$A_{4}$ & 0.02 & 0.03 & 0.10 & 0.02 & 0.03 & 0.12 & 0.01 & 0.13 & 0.02 & 0.02 & 0.00 & 0.00 & 0.03 & 0.00 & 0.04 \\
\hline$A_{5}$ & 0.01 & 0.01 & 0.01 & 0.03 & 0.01 & 0.01 & 0.00 & 0.06 & 0.01 & 0.01 & 0.00 & 0.00 & 0.01 & 0.00 & 0.01 \\
\hline$A_{6}$ & 0.02 & 0.02 & 0.03 & 0.08 & 0.05 & 0.04 & 0.01 & 0.11 & 0.02 & 0.01 & 0.00 & 0.00 & 0.07 & 0.00 & 0.11 \\
\hline$A_{7}$ & 0.11 & 0.14 & 0.16 & 0.13 & 0.14 & 0.20 & 0.02 & 0.18 & 0.11 & 0.06 & 0.01 & 0.00 & 0.11 & 0.01 & 0.16 \\
\hline$A_{8}$ & 0.12 & 0.16 & 0.16 & 0.13 & 0.17 & 0.20 & 0.05 & 0.09 & 0.11 & 0.10 & 0.01 & 0.00 & 0.13 & 0.01 & 0.19 \\
\hline$A_{9}$ & 0.03 & 0.16 & 0.18 & 0.06 & 0.18 & 0.18 & 0.06 & 0.16 & 0.04 & 0.06 & 0.01 & 0.00 & 0.11 & 0.09 & 0.19 \\
\hline$A_{10}$ & 0.00 & 0.01 & 0.01 & 0.10 & 0.11 & 0.05 & 0.00 & 0.02 & 0.01 & 0.01 & 0.03 & 0.00 & 0.06 & 0.00 & 0.01 \\
\hline$A_{11}$ & 0.02 & 0.04 & 0.06 & 0.15 & 0.13 & 0.15 & 0.02 & 0.07 & 0.08 & 0.10 & 0.01 & 0.00 & 0.07 & 0.09 & 0.13 \\
\hline$A_{12}$ & 0.01 & 0.02 & 0.03 & 0.14 & 0.11 & 0.10 & 0.01 & 0.09 & 0.01 & 0.09 & 0.06 & 0.00 & 0.08 & 0.01 & 0.03 \\
\hline$A_{13}$ & 0.01 & 0.01 & 0.03 & 0.13 & 0.02 & 0.11 & 0.01 & 0.03 & 0.01 & 0.01 & 0.05 & 0.00 & 0.02 & 0.01 & 0.08 \\
\hline$A_{14}$ & 0.12 & 0.16 & 0.21 & 0.13 & 0.14 & 0.24 & 0.13 & 0.21 & 0.13 & 0.10 & 0.04 & 0.00 & 0.15 & 0.02 & 0.22 \\
\hline$A_{15}$ & 0.06 & 0.11 & 0.17 & 0.08 & 0.13 & 0.20 & 0.10 & 0.15 & 0.11 & 0.06 & 0.01 & 0.00 & 0.08 & 0.04 & 0.08 \\
\hline
\end{tabular}

\subsubsection{Calculate centrality and cause}

The total impact degree of the influencing factor set was calculated according to Eq. (3) and Eq. (4). The results are shown in Tab. 3. $C$ stands for the total impact degree of the other influencing factors on the test factor, and $R$ represents the total impact degree of the test factor on other factors. $N=R-C$ is the cause and $M=R+C$ is the centrality. The cause-and-effect diagram of the influencing factors was drawn using $M$ as the $y$-axis and $N$ as the X-axis (Fig. 3).

Table 3 Total impact of influencing factors of runway incursion

\begin{tabular}{|c|c|c|c|c|c|c|c|c|c|c|c|c|c|c|c|}
\hline & $A_{1}$ & $A_{2}$ & $A_{3}$ & $A_{4}$ & $A_{5}$ & $A_{6}$ & $A_{7}$ & $A_{8}$ & $A_{9}$ & $A_{10}$ & $A_{11}$ & $A_{12}$ & $A_{13}$ & $A_{14}$ & $A_{15}$ \\
\hline$C$ & 0.67 & 0.79 & 0.90 & 0.55 & 0.18 & 0.59 & 1.56 & 1.65 & 1.52 & 0.42 & 1.09 & 0.78 & 0.52 & 2.00 & 1.38 \\
\hline$R$ & 0.55 & 1.10 & 1.47 & 1.27 & 1.60 & 1.93 & 0.45 & 1.53 & 0.75 & 0.73 & 0.24 & 0.00 & 1.11 & 0.30 & 1.57 \\
\hline$N=R-C$ & 0.12 & -0.30 & -0.57 & -0.71 & -1.42 & -1.34 & 1.11 & 0.12 & 0.77 & -0.30 & 0.85 & 0.78 & -0.59 & 1.70 & -0.20 \\
\hline$M=R+C$ & 1.22 & 1.89 & 2.37 & 1.82 & 1.78 & 2.52 & 2.01 & 3.18 & 2.27 & 1.15 & 1.33 & 0.78 & 1.63 & 2.31 & 2.95 \\
\hline
\end{tabular}




\subsubsection{Cause-and-effect analysis of influencing factor set}

(1) Analysis of the importance of factors

Tab. 3 shows that $A_{8}, A_{15}, A_{6}, A_{14}, A_{9}$ and $A_{3}$ have high centrality $(R+C)$ values, indicating that they have great impacts on runway incursion. Among them, $A_{8}$ is a connecting factor in the influencing factor set and is influenced by causal factors and influences the consequence factors. This indicates that executing safety management systems and regulations strictly is the major means of incursion risk control. Fig. 3 shows that these factors occupy important nodes and are closely related with other factors. $A_{12}, A_{10}, A_{1}$ and $A_{11}$ are less important, indicating that they are relatively independent from other factors.

(2) Analysis of causal factors

Tab. 3 shows that factors with positive $R-C$ values are cause factors and occupy the right region of Fig. 3. $A_{14}$ shows the highest $R-C$, followed by $A_{7}, A_{11}, A_{12}, A_{9}, A_{1}$ and $A_{8}$ successively. Among them, $A_{14}$ influences other factors most and is recognized as the root cause. $A_{7}$ and $A_{8}$ are important management means that affect the behaviors of subjects, such as pilots, air traffic controllers, and drivers. $A_{9}$ and $A_{1}$ can avoid negligence and operational error by improving the safety concept and operational skills of employees. $A_{11}$ and $A_{12}$ are less influenced by other factors, but have great impacts on other factors.

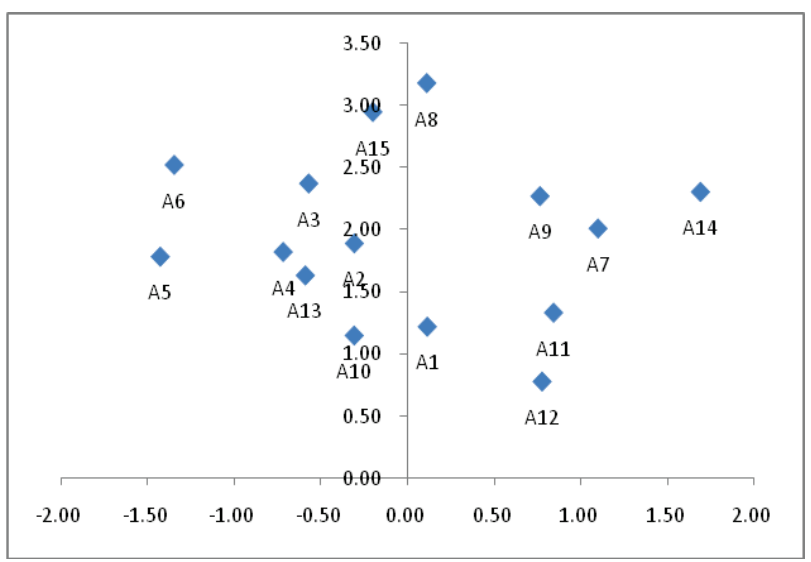

(3) Analysis of consequence factors

Tab. 4 shows that factors with negative $R-C$ values are consequence factors that occupy the left region of Fig. 3. $A_{5}$ has the highest absolute $R-C$ value, followed by $A_{6}, A_{4}, A_{3}, A_{2}, A_{15}$ and $A_{10}$ successively. $A_{5}$ and $A_{6}$ are the most sensitive consequence factors to other factors and consistent with management practices. They are direct causes of runway incursion. $A_{4}, A_{3}$ and $A_{2}$ influence runway incursion indirectly by $A_{5} . A_{15}$ and $A_{10}$ represent hardware facilities and are environmental factors. They can influence $A_{5}$ and $A_{6}$ indirectly.

\subsection{ISM analysis \\ 4.3.1 Establishment of ISM}

From the associated achievements perspective, $\lambda$ can be determined in three ways. The first one is through the multi-expert joint determination method [24, 25], which emphasizes the joint determination of multiple experts ambiguously, but does not illustrate how to eliminate the error from the subjectivity of experts. The second one is through the averaging method $[19,26]$, which determines $\lambda$ by calculating the mean of elements in $T$. The third one is through the determination method based on statistical distribution [27]. It proposes that $\lambda=\mu+0.5 \sigma$ and is an extension of the averaging method, where $\mu$ and $\sigma$ are the mean and the standard deviation of elements in $T$. It considers the internal law of normal data distribution. In this study, the threshold was determined by the third one.

$\mu=0.065$ and $\sigma=0.0608$.

Therefore, $\lambda=\mu+0.5 \sigma=0.0954$

By substituting $\lambda=0.0954$ into Eq. (5) and Eq. (6), the weak relationships of the factors are eliminated. The reachable matrix $(\boldsymbol{K})$ of the influencing factor set was constructed (Tab. 4). The reachable and antecedent sets of the influencing factors were determined according to Eq. (7) and Eq. (8). The factors were layered according to Eq. (9) and Eq. (10). The results are shown in Tab. 5. ISM was established according to the consequence priority (Fig. 4). Grey nodes are causal factors and the rest are consequence factors.

Figure 3 Influence relationship diagram of influencing factors

Table 4 Reachable matrix $\mathrm{K}$ of influencing factors of runway incursion

\begin{tabular}{|c|c|c|c|c|c|c|c|c|c|c|c|c|c|c|c|}
\hline $\mathrm{K}$ & $A_{1}$ & $A_{2}$ & $A_{3}$ & $A_{4}$ & $A_{5}$ & $A_{6}$ & $A_{7}$ & $A_{8}$ & $A_{9}$ & $A_{10}$ & $A_{11}$ & $A_{12}$ & $A_{13}$ & $A_{14}$ & $A_{15}$ \\
\hline$A_{1}$ & 0 & 1 & 1 & 0 & 1 & 0 & 0 & 0 & 0 & 0 & 0 & 0 & 0 & 0 & 1 \\
\hline$A_{2}$ & 0 & 0 & 1 & 0 & 1 & 1 & 0 & 0 & 0 & 0 & 0 & 0 & 0 & 0 & 0 \\
\hline$A_{3}$ & 0 & 0 & 0 & 0 & 1 & 1 & 0 & 1 & 0 & 0 & 0 & 0 & 0 & 0 & 1 \\
\hline$A_{4}$ & 0 & 0 & 1 & 0 & 0 & 1 & 0 & 1 & 0 & 0 & 0 & 0 & 0 & 0 & 0 \\
\hline$A_{5}$ & 0 & 0 & 0 & 0 & 0 & 0 & 0 & 0 & 0 & 0 & 0 & 0 & 0 & 0 & 0 \\
\hline$A_{6}$ & 0 & 0 & 0 & 0 & 0 & 0 & 0 & 1 & 0 & 0 & 0 & 0 & 0 & 0 & 1 \\
\hline$A_{7}$ & 1 & 1 & 1 & 1 & 1 & 1 & 0 & 1 & 1 & 0 & 0 & 0 & 1 & 0 & 1 \\
\hline$A_{8}$ & 1 & 1 & 1 & 1 & 1 & 1 & 0 & 0 & 1 & 1 & 0 & 0 & 1 & 0 & 1 \\
\hline$A_{9}$ & 0 & 1 & 1 & 0 & 1 & 1 & 0 & 1 & 0 & 0 & 0 & 0 & 1 & 0 & 1 \\
\hline$A_{10}$ & 0 & 0 & 0 & 1 & 1 & 0 & 0 & 0 & 0 & 0 & 0 & 0 & 0 & 0 & 0 \\
\hline$A_{11}$ & 0 & 0 & 0 & 1 & 1 & 1 & 0 & 0 & 0 & 1 & 0 & 0 & 0 & 0 & 1 \\
\hline$A_{12}$ & 0 & 0 & 0 & 1 & 1 & 1 & 0 & 0 & 0 & 0 & 0 & 0 & 0 & 0 & 0 \\
\hline$A_{13}$ & 0 & 0 & 0 & 1 & 0 & 1 & 0 & 0 & 0 & 0 & 0 & 0 & 0 & 0 & 0 \\
\hline$A_{14}$ & 1 & 1 & 1 & 1 & 1 & 1 & 1 & 1 & 1 & 1 & 0 & 0 & 1 & 0 & 1 \\
\hline$A_{15}$ & 0 & 1 & 1 & 0 & 1 & 1 & 1 & 1 & 1 & 0 & 0 & 0 & 0 & 0 & 0 \\
\hline
\end{tabular}




\begin{tabular}{|c|c|c|c|c|c|}
\hline \multirow{2}{*}{ No. } & \multirow{2}{*}{ Layer } & Cause priority & Consequence priority & \multirow{2}{*}{ Common factors } & $\begin{array}{c}\text { Activity } \\
\text { factors }\end{array}$ \\
\cline { 3 - 4 } & & Factors of different layers & Factors of different layers & & \\
\hline 0 & Super layer & 5,6 & 5,6 & $1,2,3,4,13,15$ & 10 \\
\hline 1 & Middle layer & $1,2,3,4,13,15$ & $1,2,3,4,13,15,10$ & $7,8,9$ & 11,12 \\
\hline 2 & Deep layer & $7,8,9$ & $7,8,9,11,12$ & 14 & $10,11,12$ \\
\hline 3 & Root layer & $10,11,12,14$ & 14 & 14 & 12 \\
\hline
\end{tabular}

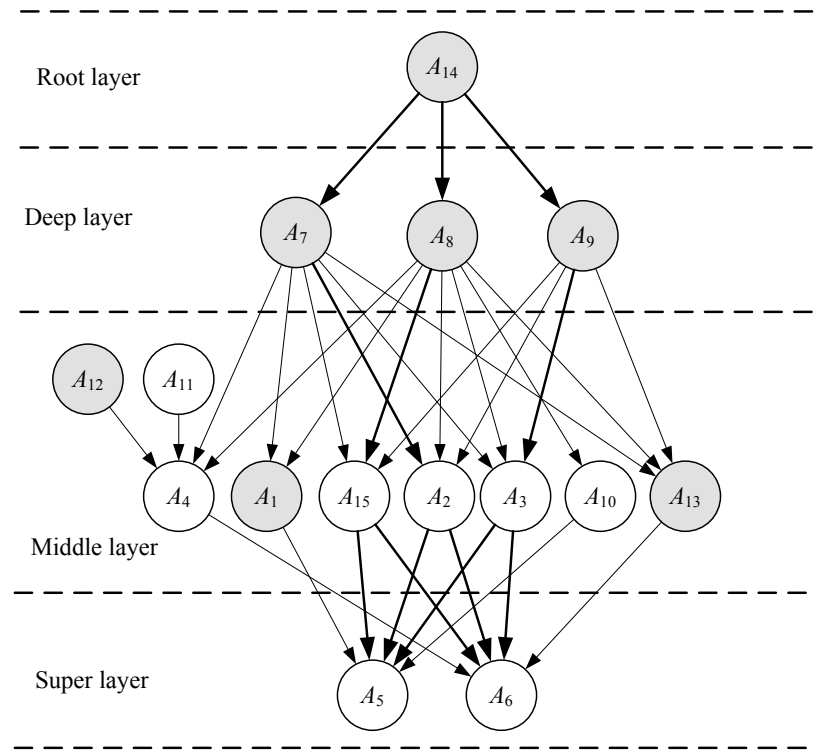

Figure 4 ISM of influencing factors of runway incursion

\subsubsection{ISM analysis}

Tab. 5 shows that $A_{14}$ is in Layer 3 and is the root cause of runway incursion. Therefore, airports shall improve safety management in the strategic level. The attention of airport senior managers on safety influences runway incursion indirectly through $A_{7}, A_{8}$, and $A_{9}$, which are in Layer 2. Perfection and the strict implementation of systems as well as training are deep factors that prevent runway incursion. $A_{5}$ and $A_{6}$ are in Layer 0 in Tab. 5 and are superficial and direct causes of runway incursion. These prove the internal consistency between DEMATEL and ISM. $A_{1}, A_{2}, A_{3}, A_{4}, A_{13}$ and $A_{15}$ are in Layer 1 of the ISM. They influence $A_{5}$ and $A_{6}$, but are influenced by deep and root factors. They are in the middle layer.

The activity factors in ISM are the exogenous variables of the system or are slightly influenced by other factors. They are the keys of system analysis. $A_{10}, A_{11}$ and $A_{12}$ are the activity factors in the ISM, and no superior factors exist, indicating that they are less influenced by external factors. This conforms to the results of DEMATEL. Airport shall enhance countermeasures for tough meteorological conditions and the busy state, and improve airport surface conditions. These factors are free from the intervention of the upper layer and easily induce runway incursion.

ISM has multiple risk transmission paths (Fig. 4). The dominant way is $A_{14} \rightarrow A_{7}+A_{8}+A_{9} \rightarrow A_{15}+A_{2}+$ $A_{3} \rightarrow A_{5}+A_{6}$. This is the improved way of runway incursion control. The senior safety management of airports influences $A_{5}$ and $A_{6}$ through different ways. Attention should be given to the positive enhancement of different ways of avoiding the evolution of runway incursion risks.

\section{Conclusions}

The influencing factors of runway incursion and their interaction mechanism were discussed in this study. Direct relationships among influencing factors and relation strengths were analyzed through DEMATEL and ISM. The cause-and-effect diagram and ISM were established and used to determine the importance of influencing factors, respectively. Root causes, deep influencing factors, and direct influencing factors were identified. The following conclusions are drawn:

(1) The cause and effect of influencing factors can be distinguished better based on DEMATEL-ISM. Inadequate attention of leaders to safety $\left(A_{14}\right)$, absent safety management system $\left(A_{7}\right)$, busy airport business $\left(A_{11}\right)$, and complicated meteorological conditions $\left(A_{12}\right)$ are cause factors, while the high rate of judgment and operational error $\left(A_{5}\right)$, the oversight of ground officials $\left(A_{6}\right)$, heavy work load $\left(A_{4}\right)$, and weak safety consciousness $\left(A_{3}\right)$ are consequence factors. Cause factors influence consequence factors.

(2) Influencing factors can be layered and risk transmission paths can be determined accurately by DEMATEL-ISM. The inadequate attention of leaders to safety $\left(A_{14}\right)$ is the root cause of runway incursion. The absence of a safety management system $\left(A_{7}\right)$, invalid safety management system $\left(A_{8}\right)$, and poor safety education $\left(A_{9}\right)$ are deep influencing factors. The high rate of judgment and operational error $\left(A_{5}\right)$ and the oversight of ground officials $\left(A_{6}\right)$ are direct influencing factors and causes of runway incursion. The influencing paths of factors are paths to improving safety control.

(3) The relationships among influencing factors and their interaction mechanism can be explored by DEMATEL-ISM. It provides a simple and reliable analysis model for recognizing the importance of risk factors, influencing layers, and influencing paths in aviation safety management.

DEMATEL-ISM can divide the influencing factors of runway incursion into different layers. It focuses on the improvement of cause factors and corresponding countermeasures to control runway incursion risks better. "Inadequate attention of airport leaders to safety" is in the root layer. To avoid runway incursion risks, airport senior managers should give significant attention to safety, improve the "safety culture" of the organization by perfecting the "safety management system" and "safety education", enhance the "experiences and skills" and "safety consciousness" of the staff, promote the "implementation of safety management system", increase "ground supervision", and decrease the "judgment and operational error" of workers.

The cause-and-effect diagram and ISM were established in this study and are conducive to identifying cause and consequence factors, layering of influencing factors, and determining risk transmission paths. They can provide accurate theoretical support to runway incursion 
risk control. However, further studies on how runway incursion risks transmit to different layers and how to intercept transmission paths and enhance the runway incursion control system are required.

\section{Acknowledgements}

The study was supported by the National Social Science Foundation of China (No. 71271163).

\section{References}

[1] Huo, Z. Q.; Han, S. C. Analysis on the threats and errors caused by the runway incursions and corresponding controlling ways. // Journal of Safety and Environment, 12, 4(2012), pp. 192-196.

[2] Zhang, X. Q.; Yang, W. T. Reason analysis of runway incursions based on grey theory. // Journal of Safety and Environment, 10, 5(2010), pp. 160-162.

[3] Tian, J.; Zhou, Y. Hazards analysis method based on scenario simulation of runway incursion. // China Safety Science Journal, 26, 6(2016), pp. 111-116.

[4] Luo, J.; Lin, X. N., Li, Y. Research on the algorithms of runway incursion severity classification and its application. // Journal of Safety and Environment, 13, 4(2013), pp. 227231.

[5] Feigh, K. M.; Bruneau, D. P. J. Incorporating controller intent into a runway incursion prevention system. // IEEE Digital Avionics Systems Conference / Orlando, 2009, pp. 113.

[6] Adam, G. L.; Lentz, R. H.; Bair, R. W. Study of the causes of runway incursions and related incidents. // The First IEEE Conference on Control Applications / Dayton, 1992, pp. 539-543. https://doi.org/10.1109/CCA.1992.269816

[7] Chang, Y. H.; Wong, K. M. Human risk factors associated with runway incursions. // Journal of Air Transport Management, 24, 9(2012), pp. 25-30. https://doi.org/10.1016/j.jairtraman.2012.05.004

[8] Luo, J.; Lin, X. N. Runway incursion risk assessment based on fuzzy sets theory and improved TOPSIS method. // China Safety Science Journal, 22, 12(2012), pp. 116-121.

[9] Luo, J.; Lin, X. N.; Yan, Y. G. Analysis of runway incursion influence factors based on Gaussian Bayesian network model. // Journal of Safety and Environment, 12, 3(2012), pp. 196-199.

[10] Yuan, L. P.; Sun, R. S.; Cheng, M. Study on safety assessment of runway incursion based on ETA and CREAM. // Flight Dynamics, 33, 2(2015), pp. 187-192.

[11] Kim, D.; Yang, H. Evaluation of the risk frequency for hazards of runway incursion in Korea. // Journal of Air Transport Management, 23, 8(2012), pp. 31-35. https://doi.org/10.1016/j.jairtraman.2012.01.011

[12] Lin, X. N. Research of Runway Incursion formation mechanism and risk management. // Master's Thesis of Civil Aviation Flight University of China, Sichuan, China, 2013.

[13] Gao, Y.; Luo, X. F. Research on risk of airport based on Bowtie model. // Journal of Safety Science and Technology, 5, 5(2009), pp. 83-87.

[14] Stroeve, S. H.; Blom, H. A. P.; Bakker, G. J. Systemic accident risk assessment in air traffic by Monte Carlo simulation. // Safety Science, 47, 2(2009), pp. 238-249. https://doi.org/10.1016/j.ssci.2008.04.003

[15] Landry, S. J.; Chen, X. W.; Nof, S.Y. A decision support methodology for dynamic taxiway and runway conflict prevention. // Decision Support Systems, 55, 1(2013), pp. 165-174. https://doi.org/10.1016/j.dss.2013.01.016

[16] Zhou, D .Q.; Zhang, L. Establishing hierarchy structure in complex systems based on the integration of DEMATEL and ISM. // Journal of Management Sciences in China, 11, 2(2008), pp. 20-26.

[17] Csaszar F A, Eggers J P Organizational decision making: An information aggregation view. // Management Science, 59, 10(2013), pp. 2257-2277. https://doi.org/10.1287/mnsc.1120.1698

[18] Shaik, M. N.; Abdul-Kader, W. Comprehensive performance measurement and causal-effect decision making model for reverse logistics enterprise. // Computers \& Industrial Engineering, 68, 2(2014), pp. 87-103. https://doi.org/10.1016/j.cie.2013.12.008

[19] Cebi, S. Determining importance degrees of website design parameters based on interactions and types of websites. // Decision Support Systems, 54, 2(2013), pp. 1030-1043. https://doi.org/10.1016/j.dss.2012.10.036

[20] Hsu, C. W.; Kuo, T. C.; Chen, S. H.; et al. Using DEMATELto develop a carbon management model of supplier selection in green supply chain management. // Journal of Cleaner Production, 56, 10(2013), pp. 164-172. https://doi.org/10.1016/j.jclepro.2011.09.012

[21] Liou, J. J. H.; Yen, L.; Tzeng, G. H. Building an effective safety management system for airlines. // Journal of Air Transport Management, 14, 1(2008), pp. 20-26. https://doi.org/10.1016/j.jairtraman.2007.10.002

[22] Liu, H. C.; You, J. X.; Lu, C.; et al. Evaluating health-care waste treatment technologies using a hybrid multi-criteria decision making model. // Renewable and Sustainable Energy Reviews, 41, 1(2015), pp. 932-942. https://doi.org/10.1016/j.rser.2014.08.061

[23] Seyed-Hosseini, S. M.; Safaei, N.; Asgharpour, M. J. Reprioritization of failures in a system failure mode and effects analysis by decision making trial and evaluation laboratory technique. // Reliability Engineering \& System Safety, 91, 8(2006), pp. 872-881. https://doi.org/10.1016/j.ress.2005.09.005

[24] Li, Y.; Hu, Y.; Zhang, X.; et al. An evidential DEMATEL method to identify critical success factors in emergency management. // Applied Soft Computing, 22, 5(2014), pp. 504-510. https://doi.org/10.1016/j.asoc.2014.03.042

[25] Hsu, C. C. Evaluation criteria for blog design and analysis of causal relationships using factor analysis and DEMATEL. // Expert Systems with Applications, 39, 1(2012), pp. 187-193. https://doi.org/10.1016/j.eswa.2011.07.006

[26] Wu, H. H.; Chen, H. K.; Shieh, J. I. Evaluating performance criteria of employment service outreach program personnel by DEMATEL method. // Expert Systems with Applications, 37, 7(2010), pp. 5219-5223. https://doi.org/10.1016/j.eswa.2009.12.068

[27] Tzeng, G. H.; Huang, C. Y. Combined DEMATEL technique with hybrid MCDM methods for creating the aspired intelligent global manufacturing \& logistics systems. // Annals of Operations Research, 197, 1(2012), pp. 159190. https://doi.org/10.1007/s10479-010-0829-4

\section{Authors' addresses}

\section{Pan-ke Zhang, Ph.D. Candidate}

(Corresponding author)

Room 525, College of Management, Wuhan University of

Technology, No. 122 Luoshi Road,

430070, Wuhan, Hubei Province, P. R. China

E-mail: cnzpk@163.com

College of Management, Henan University of Science and Technology, Luoyang, P. R. China

\section{Fan Luo, Ph.D., Professor}

Room 525, College of Management, Wuhan University of Technology, No. 122 Luoshi Road,

430070, Wuhan, Hubei Province, P. R. China.

E-mail: sailluo@163.com 